cisions, particularly vital in gross hand injuries. By constantly regarding the hand as a composite functioning unit, the optimum ultimate result may be achieved for in the author's words: 'Hand surgery must not be fragmented into separate systems.'

Only too often extensor tendon injuries are considered to present no difficulty in repair with the aim of a good or even excellent result easily achieved and this in spite of the indifferent results frequently following the commonest extensor lesion, the mallet finger. In drawing attention to the peculiar and largely anatomical problems attending these injuries Bank and Wakefield aim at a degree of perfection which exemplifies the high standard they set in the treatment of all hand injuries.

Sections of particular interest in a well-planned work are those on the surgical anatomy of the hand and the special aspects of burns and injuries in children. The book is profusely illustrated by photographs and line drawings and well-produced. by the publishers.

\section{TEXTBOOK OF GENETICS}

By William Hovanitz, Ph.D. Pp. $x+419$, with 267 illustrations. London: Elsevier Publishing Co., Ltd. Distributors Cleaver-Hume Press. 1953. 42s. 6d.

The scope of Professor Hovanitz's book is considerable and it is probable that some of its less satisfactory features are due to the endeavour to compress too much information into too few pages. A short preface reminds the reader of what he should know and may have forgotten and also gives a summary of the author's philosophical approach to genetics. In common with the rest of the book, and with a greater frequency, the preface is marred by what appear to be printer's errors and also by examples of almost meaningless phraseology. For the most part, however, the book is clearly written. Excellent introductory chapters deal with Mendelism and explain the mathematics of probability, but the manner of presentation of some later chapters is less happy. For instance the statement is made that achondroplasia is a simple inherited condition which usually appears as a dominant; this statement is accompanied by a pedigree in which the symbols are unexplained, but whatever interpretation one gives to them the pedigree does not appear to illustrate the behaviour of a dominant. Similarly the references to the inheritance of comb-structure of the fowl, although undoubtedly quite clear to a practiced geneticist would be difficult for a student or non-specialist to understand because they contain words used in an inexact manner. The sections dealing with plant genetics are accompanied by an excellent account of gametogenesis and embryogenesis of plants - an account that many writers of botanical textbooks might well study. The chromosome is described very clearly both from the cytological and cytochemical aspects. Most of the remainder of the book deals with complicated genetical phenomena, some of which, notably the shell-coiling of snails, are dismissed so concisely as to be incomprehensible. In this example matters are not improved by a textual error that has introduced a new and unexplained gene. Modern studies of the genetics of bacteria are scarcely touched on; viruses are not mentioned.

At intervals the book contains unanswered questions designed to arouse curiosity and the desire to investigate. Surely no one but a serious student would be reading this work and he would be better helped by questions to which he could check his answer. The omission of adequate references to work cited is a grave fault and should be rectified in any subsequent edition. In general, however, the book is stimulating and informative and provides a useful addition to the literature of the subject.

A.F.

\section{M.R.C. Special Report Series, No. 280 VITAMIN C REQUIREMENT OF HUMAN ADULTS}

\section{A Report by the Vitamin C Sub-Committee of the Accessory Food Factors Committee}

Compiled-by W. Bartley, H. A. Krebs and J. R. P. O'Brien. Pp. viii + I79, with 24 illustrations, 6 in colour. London: H.M.S.O. 1953. 17s. 6d.

This publication contains the detailed aspects of the vitamin $\mathbf{C}$ deprivation experiment carried out on human volunteers towards the end of the war. A brief report of the main findings appeared in The Lancet in 1948. A detailed index is lacking but the subdivision into three main sections allows easy reference to the many clinical, biochemical and metabolic aspects of vitamin $\mathrm{C}$ deficiency that have been covered. Many of the earlier problems of the diagnosis of scurvy have been overcome by diligent observation which forms a striking characteristic in this brilliant experiment. The relative inadequacy of biochemical methods as compared with clinical observation in the diagnosis of early scurvy is well illustrated and previous reports that wound healing becomes delayed only after the appearance of clinical scurvy are confirmed. In the achievement of its primary object, however, the report is outstanding in that it presents convincing evidence that the minimum daily requirement of vitamin $C$ for the prevention of scurvy in healthy adults not undertaking strenuous physical work is in the region of only ro mg.

To those with special interests in vitamin C metabolism criticism could only be levelled in that the publication was not more detailed in certain aspects. The comparatively large section devoted to follicular hyperkeratosis stresses the importance of this physical sign as a simple diagnostic tool but little mention is made of its characteristic distribution and the possible influence, as seen in this survey, that clothing or other external agents may have in this regard. Those with experience of clinical scurvy will note that the stage of extensive ecchymoses and intramuscular haematomata was not reached in this study and may feel that this 